\title{
SMALL DREAMS OF GRANDEUR
}

\author{
Scientist: \\ Abigail Smith \\ Artist: \\ Katherine Steeds
}

STONE, SEAWATER, SHELLS, STONE:

\begin{abstract}
Abigail Smith
People ask," "and what do you do?" I could say l'm a carbonate geobiochemist, but that doesn't explain much. Often I just say "I study shells." But really, I study the journey from stone to seawater through shell back to stone. It takes some geology, a bit of chemistry and a fair understanding of marine biology to get at the guts of this process. I'm a jack-of-all-trades, as long as it involves calcium carbonate.
\end{abstract}

\section{From Stones to Seawater}

Chemicals get into the sea mostly from weathering - rocks wear down and dissolve; and elements like calcium find their way into waterways, and eventually the sea. After sodium and chloride (salt), calcium is one of the most common elements dissolved in seawater, usually hovering about 0.04 percent.' That doesn't seem like much, but there's a lot of seawater, so there's a lot of calcium. All living things need and use calcium. In fact, it's the most common mineral in people, in bones and teeth. ${ }^{2}$

\section{From Seawater to Shells}

If you combine calcium with a carbon and three oxygens, you get calcium carbonate $\left(\mathrm{CaCO}_{3}\right)$. This common mineral is known by lots of names: lime, chalk, shell, limestone, calcite, onyx, marble. There's plenty of carbon and oxygen in the sea, so making calcium carbonate from seawater is something many creatures do. They make shells, skeletons, eggshells: in myriad forms, all complexly engineered, all beautiful.

Think about a delicately-pigmented snail shell, produced by a squishy mollusc for protection. Consider the thick ropy white castle of the barnacle, complete with doors that open and close. Imagine the iridescent glory of the inside of a pāua shell, or the elegant spines of an urchin. All calcium carbonate, all harvested from seawater and pressed into service (Figure I).

\section{Special Shells}

It was during my PhD study in the early 1990s when I first encountered a very poorly known, but simply lovely group of critters - their delicate skeletons captured me with their versatility, their regularity and their beauty. Let me tell you about bryozoans. 

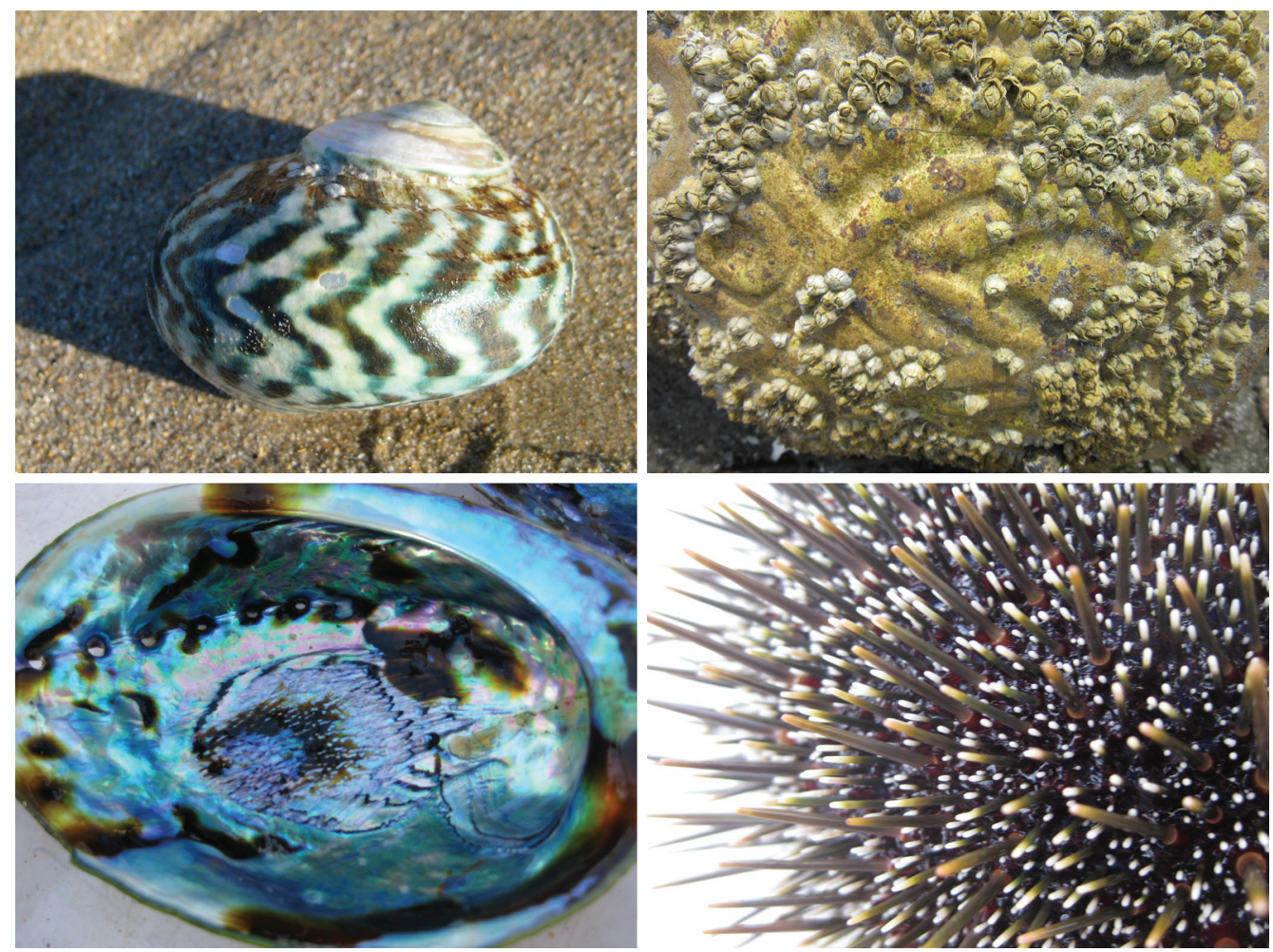

Figure I. Many amazing ways animals can make seawater into shells.

The name bryozoans means "moss animals," because they are tiny animals who group together to make colonies that are vaguely plant-like. Another name for them is "lace corals," because of their net-like forms and their colonial lifestyle - they are not really related to corals. They aren't edible, they are very small and they often live in deep water or under rocks - so they aren't known to every beachcomber. ${ }^{3}$
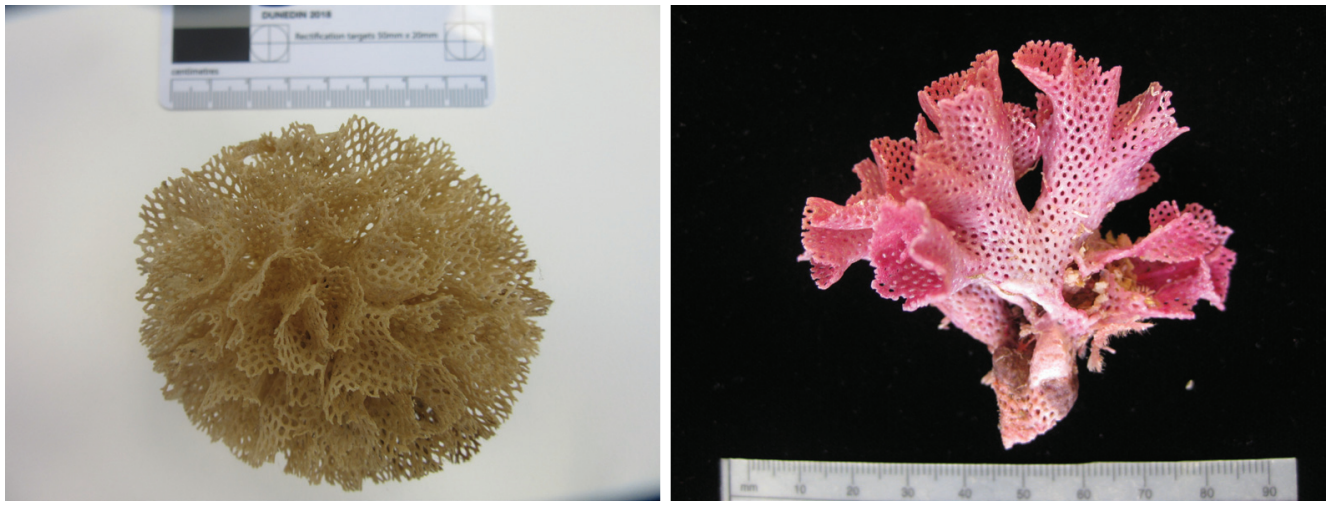

Figure 2. Examples of "lace coral" or a bryozoan colony - about $12 \mathrm{~cm}$ across.

Made of millions of tiny identical boxes, each with a single individual animal living inside. 
Each tiny individual bryozoan is less than I mm across, and each of them makes a little box of calcium carbonate, connected via tubes and pipes to their neighbours. They form a colony, like a tiny apartment building - or maybe more like a mitten, where each knitted stitch has its place and role to play (Figure 3). Inside each box is a tiny critter (a polypide), which emerges with tentacles waving to catch minute food particles. Some of them don't eat - they defend the colony, or they reproduce - and are supported by their neighbours.
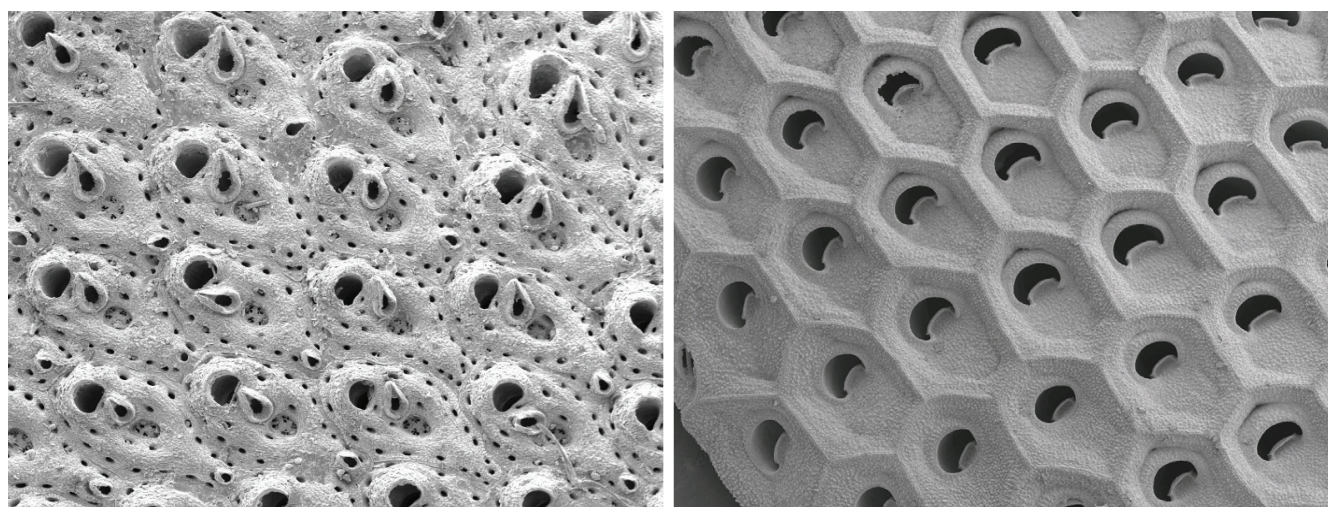

Figure 3. Close-ups of bryozoan skeletons. Each little oval box is about $0.5 \mathrm{~mm}$ long, and each hole is the door for a tiny polypide to come out.

Bryozoans are not very large or abundant in the northern hemisphere where most textbooks are written, so they are classed as a "minor" group. But in Zealandia and Australasia they are abundant, large and diverse. Zealandia alone might have a thousand species of living bryozoans, making them the fifth-most diverse group in our seas. ${ }^{4}$ And yet most people have never heard of them. You might call them marine biology's best-kept secret!
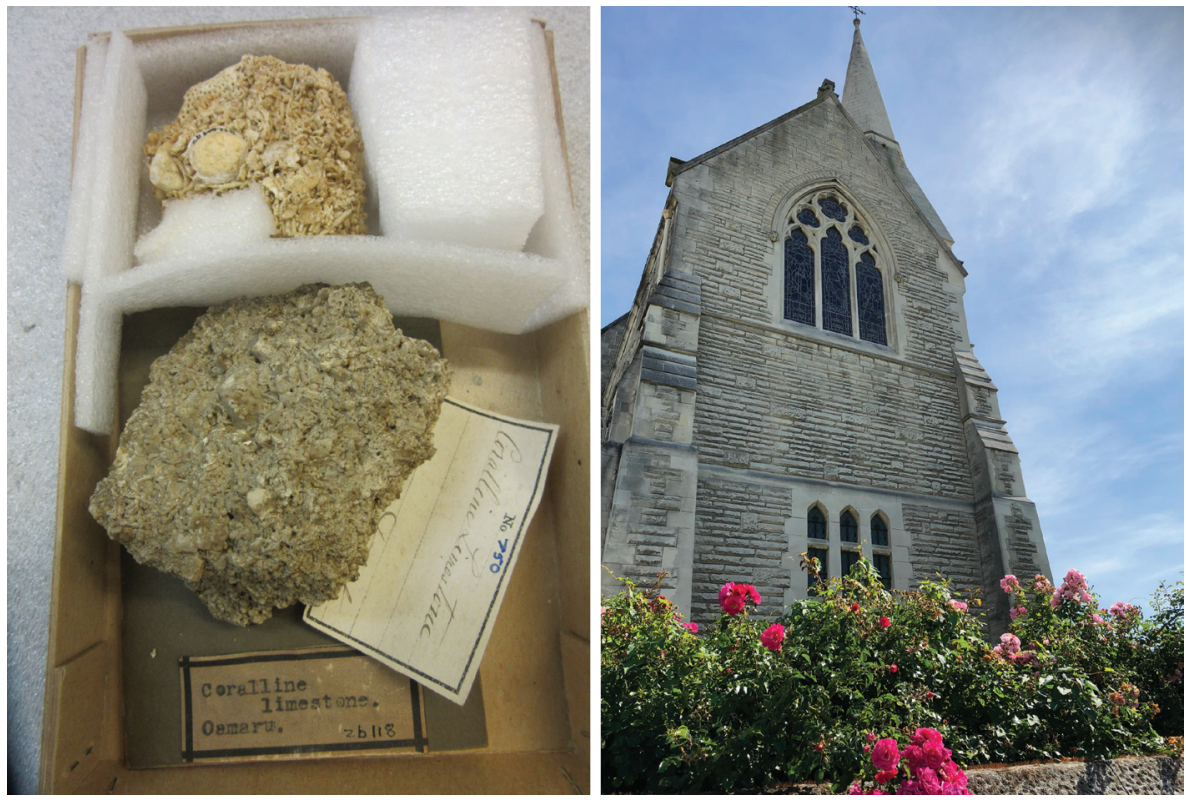

Figure 4. Left: Specimens of Oamaru stone in a museum collection.

Right: St Luke's Church in Oamaru, made entirely of Oamaru stone, full of bryozoans. 


\section{From Shells to Sand to Stone Again}

When bryozoans die, the shell remains become sand. South and east of the South Island, in water about 60-100 metres deep, lie thick deposits of bryozoan-dominated sediments. They are loose at the top, but near the bottom they are compressed and cemented, becoming limestone.

Bryozoans have been producing shells from seawater for millions of years. They are common and abundant fossils around the world. We know them here as the major component of Oamaru stone, the white limestone used in Oamaru's historic buildings, the Dunedin railway station, Knox Church and the Otago University clocktower building. If you look closely at this kind of stone, you will see the tiny tubes or branches of ancient bryozoans.

It's hard to imagine the amount of time it takes for animals smaller than I $\mathrm{mm}$ to make enough limestone for a whole city. About 35 million years ago, many kinds of bryozoans were thriving near a warm volcano - Oamaru stone is their legacy.

\section{Enthusiasm Inspires Art}

As part of the Art + Earth project, I connected with artist Kate Steeds and we talked about bryozoans. I showed her photo after photo, enthused about various publications, called her up to mention some other wonderful thing about my favourite bugs. And she responded! Her interest in natural history informed her art, and the art reflects the inspiration of the science.

The folding book she has made illustrates what makes bryozoans fascinating - and allows the reader to find it for herself. The joy of discovery and enthusiasm I get from science comes through in the experience of exploring the panels and folds of the book.
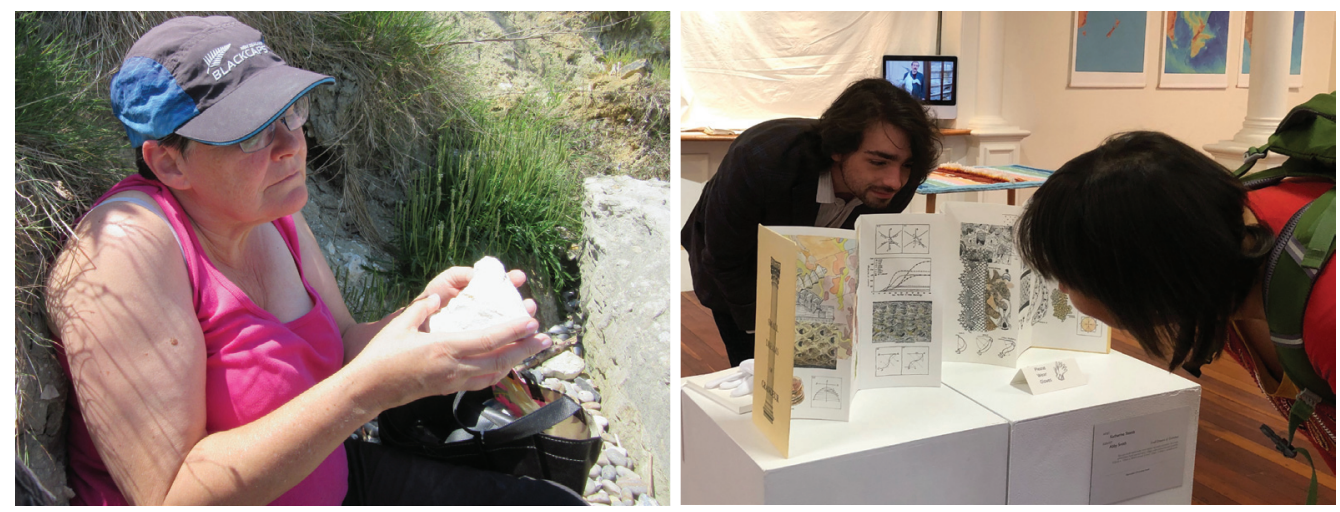

Figure 5. Scientific discovery in action. Left: Abby Smith examining limestone at a beach.

Right: Students examining the bryozoan book at the exhibition. 


\section{SMALL DREAMS OF GRANDEUR}

\section{Katherine Steeds}

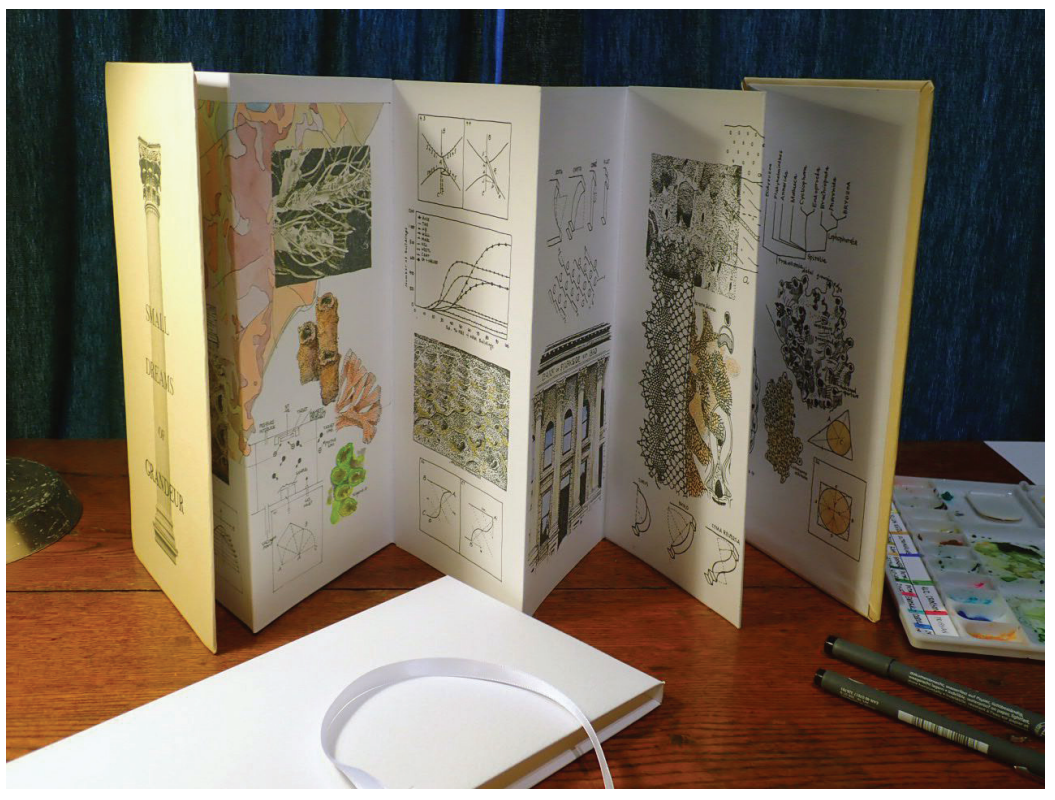

Figure 6. Katherine Steeds, Small Dreams of Grandeur, 2020, accordion-structure book, cotton paper, collage, mixed media.

\section{The Small World}

My usual focus is on the micro view and the details of the natural world. I am fascinated by fungi and lichen, flower and leaf. I have spent thousands of hours observing and photographing insects and other invertebrates all over the world. I am equally interested in their categorisation into species as I am in their forms, functions and behaviour. At times it has almost become an obsession. Recently, my imagination has been sparked by the knowledge I have gained in my partnership with Abby.

Learning a little about bryozoans has reminded me that the extraordinary complexity of a natural environment under the sea can exceed that of an ecologically rich land environment.

My resources include science graphics like graphs and maps, equipment catalogue illustrations, instruction manuals, diagrams, electron micrographs and photographs drawn from many diverse sources. In my work, I frequently like to use these kinds of image fragments as a code for my straddle stance between science and art. I am caught between my love for rational academic research of tiny elements of the natural world, on the one hand, and my drive to intuitively express the joy of my findings visually, on the other.

In this way, through a collation of drawings I have explored some of the richness of bryozoa species and their visual complexity.

However, the book I have created also explores the role of humans, their exploration and study of bryozoa, and their utilisation of their fossilised remains. The profusion and overlapping of imagery in the book points to the fascination and complexity of such an interaction. I have included references to discovery, magnification processes, identification, mapping, building, stone carving and stonemasonry. 

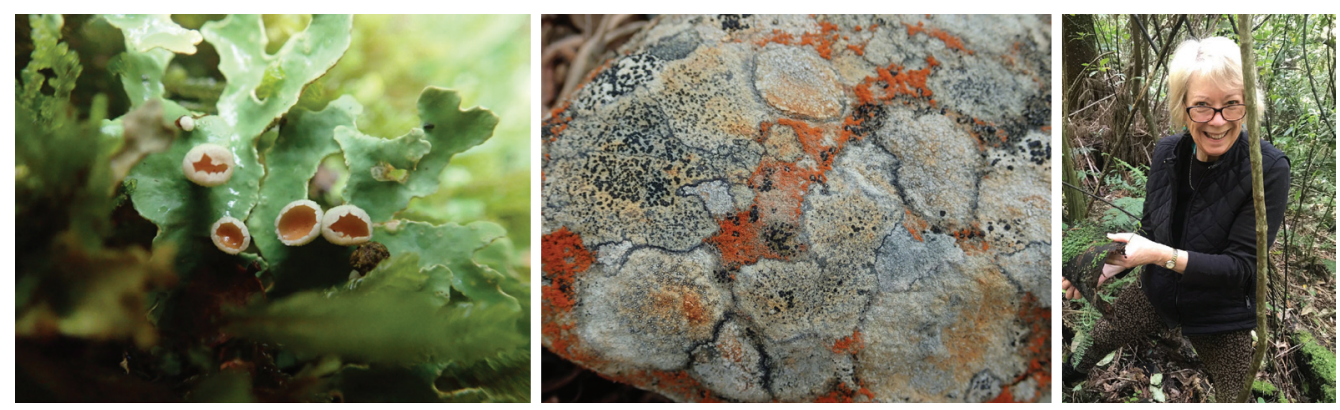

Figure 7. Field work in the bush.

I have decontextualised, then re-utilised, these visual tools, primarily for their compositional qualities - for example, their shape, colour and edge, but also with consideration for their original relevance or meaning.

Here is a series of composite and overlapping drawings, complex clonal compositions, incorporating layers of meaning and echoing the compound origins of the soft, creamy blocks of Oamaru stone. In making foreground and background ambiguous, I have suggested processes in the past that are yet ongoing - in spaces and gaps of information and relationships so far unknown.

A traditional book format echoes the customary presentation of scientific theories and discoveries, while a slip-cased accordion format allows viewers to choose where to enter the book and to influence their personal experience of participation through an unfolding, non-sequential disclosure - visually picking their way through a variety of bryozoan forms, many with intriguing appearances suggestive of more familiar objects.

In the work Small Dreams of Grandeur, Abby and I share our fascination with bryozoans. I have drawn on my thoughts about the paradoxical nature of inhabited, human-scale spaces created from stone which are the fossil remains of tiny structures created and inhabited by minute marine animals. The aim is to expand a common view of the Earth materials we sometimes fashion into buildings and decorative structures.

Solution to calcium, calcium to home, home to fossil, fossil to stone, stone to

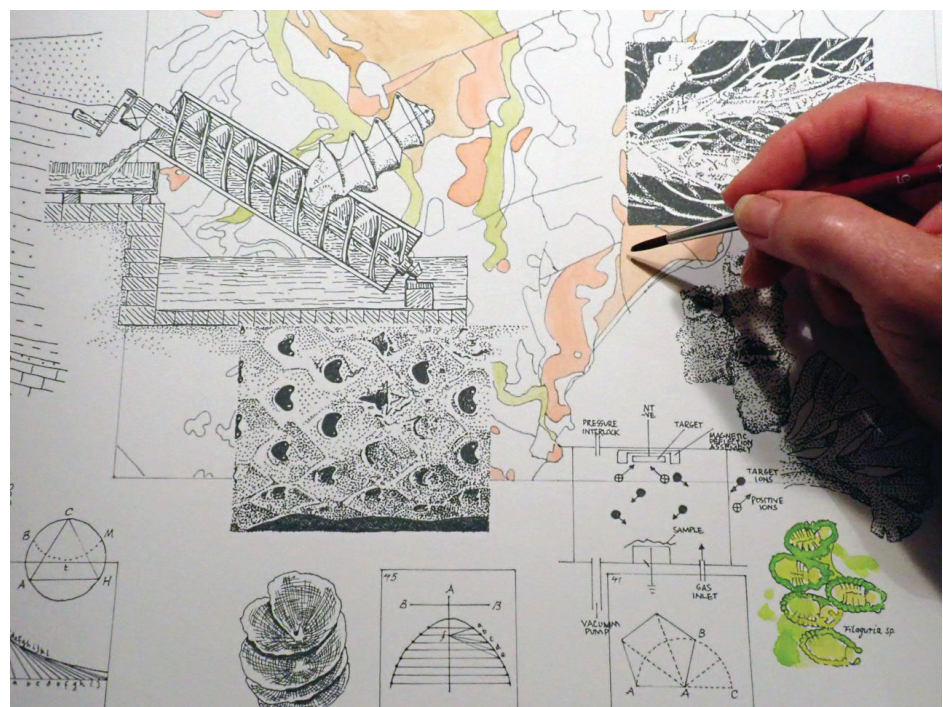

Figure 8. Work in progress. habitation.

Kate Steeds, Tauranga April 2021 
Professor Abby Smith, (ORCID ID: https://orcid.org/000-000 I-6468-9I24) Department of Marine Science, University of Otago, Dunedin, New Zealand. Abby Smith comes from New England, where early experiences wading and poking around in tidepools sent her down a marine track right from the beginning. She doublemajored in Biology and Geology at Colby College, Waterville, Maine, spending a semester at the Bermuda Biological Station, where she developed a fondness for marine carbonates. She studied for a Master's degree in the joint programme at Woods Hole and MIT. While she was there she made friends with some kiwis, one of whom she married. Later, they moved to Hamilton New Zealand, where Abby completed her DPhil at Waikato in 1991, just in time to shift to Dunedin (in southern NZ) so her husband could take up a lectureship in Zoology at the University of Otago. She has lectured and researched in the Department of Marine Science at the University of Otago since it was a Department (in 1992), serving a 4-year stint as Head of Department 20 I3-20 17. Alongside her work at the University, she was appointed to a ministerial advisory committee on Oceans Policy and chaired the Otago Conservation Board for several years, as well as having served as the Treasurer of the International Bryozoology Association for more than two decades. She was the inaugural council chair of the New Zealand Ocean Acidification Community, and has been awarded the Miriam Dell award by the NZ Association of Women in Science. She likes to stay busy, and never lets her scientific career get in the way of her other hobbies: hanging out with her two sons, knitting, making jam, and enjoying cricket.

Tauranga-based artist Katherine Steeds works painstakingly in a variety of media, focussing on details of the natural world especially that of plant, bird and insect. She bases her work on careful research and observation during travels in New Zealand and further afield, as well as from museum collections all around the world. She has a science degree and postgraduate diploma in art and design. Becoming familiar with individual species has given her a great appreciation and sense of the special value of the teeming and astonishing variety of species on Earth, and she endeavours to share this view with others through her works.

I MJ Kennish, Practical Handbook of Marine Science (Boca Raton, FL: CRC Press, 2020).

2 J Emsley, An A-Z Guide to the Elements: Nature's Building Blocks, new ed. (Oxford, UK: Oxford University Press, 20I I).

3 See, however, DP Gordon and S Mills, Bountiful Bryozoans: A Guide to the Bryozoans of New Zealand, https://niwa.co.nz/coastsand-oceans/marine-identification-guides-and-fact-sheets/Bryozoans.

4 DP Gordon, “Living Lace," New Zealand Geographic, 6 I (2003), 80-95.

5 BW Hayward, Granite and Marble: A Guide to Building Stones in New Zealand (Lower Hutt, NZ: Geological Society of New Zealand, 1987). 